Article

\title{
Citrus medica and Cinnamomum zeylanicum Essential Oils as Potential Biopreservatives against Spoilage in Low Alcohol Wine Products
}

\author{
Gregoria Mitropoulou, Anastasios Nikolaou, Valentini Santarmaki, Georgios Sgouros and \\ Yiannis Kourkoutas *(D)
}

Laboratory of Applied Microbiology and Biotechnology, Department of Molecular Biology and Genetics, Democritus University of Thrace, GR-68100 Alexandroupolis, Greece; gmitropo@mbg.duth.gr (G.M.); anikol@mbg.duth.gr (A.N.); vsantar@mbg.duth.gr (V.S.); gsgouros@mbg.duth.gr (G.S.)

* Correspondence: ikourkou@mbg.duth.gr; Tel.: +30-25510-30633

Received: 1 April 2020; Accepted: 1 May 2020; Published: 4 May 2020

\begin{abstract}
Low alcohol wine is a new entry in the global wine market, due to the increase in consumers' concern for health, economic and modern lifestyle issues. As low alcohol products are prone to spoilage, the adoption of natural-derived products with antimicrobial activity as biopreservatives seems to be an intriguing alternative. Thus, the aim of the present study was to investigate the possible antimicrobial properties of Citrus medica and Cinnamomum zeylanicum essential oils (EOs) and assess their commercial prospective in the wine industry. The main constituents identified by GC/MS analysis were limonene $(38.46 \%)$ and linalool $(35.44 \%)$ in C. medica EO, whereas trans-cinnamic-aldehyde $(63.58 \%)$ was the dominant compound in C. zeylanicum EO. The minimum inhibitory (MIC), non-inhibitory (NIC) and minimum lethal concentration (MLC) values against common wine spoilage microbes were initially determined. Subsequently, their efficiency was further validated in low alcohol $(\sim 6 \%$ vol) wines, either separately or in combination at $0.010 \%(v / v)$, as well as in wines deliberately inoculated with Gluconobacter cerinus, Oenococcus oeni, Pediococcus pentosaceus, Dekkera bruxellensis, Candida zemplinina, Hanseniaspora uvarum, Pichia guilliermondii or Zygosaccharomyces bailii. EO addition led to considerable spoilage and microbial growth delay during storage at room or refrigerated temperature, suggesting their potential use as wine biopreservatives.
\end{abstract}

Keywords: biopreservatives; essential oils; Citrus medica; Cinnamomum zeylanicum; wine spoilage; low alcohol wines

\section{Introduction}

Low alcohol wines constitute a new, fast-growing commercial area, due to major public concerns about the serious long-term health effects associated with alcohol consumption, together with consumers' preferences, which are mostly directed by modern lifestyle and economic reasons. However, low alcohol products are sensitive to spoilage and contain considerable amounts of chemical preservatives with well-known toxicity, such as sulfur dioxide (E220) and potassium metabisulfite (E224) [1,2]. Taking into account the daily wine consumption in Western countries, it is reasonable to consider that the average consumer is often subjected to levels well over the amount generally regarded as safe [3]. Thus, the use of natural agents with antimicrobial activity as biopreservatives, such as essential oils (EOs), might be of interest [4-6].

Citrus medica (citrus) and Cinnamomum zeylanicum (cinnamon) are plants with a great potential in the food industry, as several bioactive compounds with considerable beneficial effects are present in different plant parts $[7,8]$. Both citron and cinnamon and their derivatives are used in carbonated drinks and alcoholic beverages as raw materials and/or flavoring agents. Their isolated EOs were 
previously tested for potential antimicrobial activity [9-14] and validated in food systems $[8,15]$. However, their application as biopreservatives in wines is lacking.

An appropriately designed approach for the incorporation of EOs into foods (formulation strategies, efficiency and sensory issues) is a key factor for the development of novel products. Their insertion into a food matrix is considered an additional inherent factor for the delay of spoilage onset. Although several attempts have been focused on the successful addition of EOs and plant extracts on various foods $[16,17]$, only a very limited number of products are available on the market, mainly due to incompatibility with food taste, ineffectiveness owing to the interaction of bioactive substances with food components, their intense aroma [18], etc.

Hence, the aim of the present study was to assess the industrial potential of Citrus medica and Cinnamomum zeylanicum EOs to be used in low alcohol wines as a natural antimicrobial agent against common spoilage bacteria and yeasts/molds. Data suggesting significant extension of the product's shelf-life and repression of microbial growth after deliberate inoculation are presented.

\section{Materials and Methods}

\subsection{Extraction of EOs}

Citrus medica (citrus) fruits were harvested during October-November 2017. EO was obtained by hydrostillation using a Dean Stark apparatus, in which $12.06 \mathrm{~kg}$ of peeled citrus fruits (peeled and chopped into small pieces) were placed along with $6 \mathrm{~L}$ of distilled water (VIORYL S.A. Chemical and Agricultural Industry, Scientific Research S.A., Afidnes, Greece) After distillation (8 h, 90-100 $\left.{ }^{\circ} \mathrm{C}\right), 7 \mathrm{~g}$ of Citrus medica EO were collected.

Cinnamomum zeylanicum (cinnamon) EO was supplied by Charabot S.A. (Grasse, France).

\subsection{Microbial Strains and Culture Media}

Oenococcus oeni commercial starter, Pediococccus pentosaceus G22NM13, Gluconobacter cerinus A1M6, Dekkera bruxellensis $\gamma$ MC2.7, Candida zemplinina E228NL1, Hanseniaspora uvarum E15PL39, Pichia guilliermondii A10W20 and Zygosaccharomyces bailii BgW2 (Y-4) (kindly provided by Dr. Nisiotou A., Athens Wine Institute, ELGO-DIMITRA, Greece) were used in the present study.

O. oeni and P. pentosaceus were grown in MRS broth (LabM, UK) at $30^{\circ} \mathrm{C}$ for $24 \mathrm{~h}$, under anaerobic conditions (Anaerobic Jar 2.5 L, Merck Millipore, USA AnaeroGen 2.5 L Sachets, Oxoid, UK).

G. cerinus was grown in suitable culture broth $(100 \mathrm{~g} / \mathrm{L}$ glucose, $20 \mathrm{~g} / \mathrm{L}$ yeast extract, $20 \mathrm{~g} / \mathrm{L} \mathrm{CaCO} 3)$ at $30^{\circ} \mathrm{C}$ for $24 \mathrm{~h}$.

D. bruxellensis, C. zemplinina, H. uvarum, P. guilliermondii and Z. bailii were grown in YPD broth (yeast extract $10 \mathrm{~g} / \mathrm{L}$, peptone $20 \mathrm{~g} / \mathrm{L}$ and dextrose $20 \mathrm{~g} / \mathrm{L}$ ) at $30{ }^{\circ} \mathrm{C}$ for $24-48 \mathrm{~h}$.

\subsection{Low Alcohol Wine Production}

Low alcohol wine ( $\sim 6 \% \mathrm{vol})$ was produced by free kefir culture using concentrated must of "Muscat Hamburg" grape variety supplied by Tyrnavos Cooperative Winery and Distillery (Tyrnavos, Greece), as recently described [19].

\subsection{Wine Supplementation with EOs}

The produced wines were supplemented with the EOs either separately $(0.010 \%$ of each oil; 85 or 99 ppm for Citrus medica or C. zeylanicum EOs, respectively) or in combination ( $0.010 \%$ oil mixture consisting of equal volumes from each EO resulting in 92 ppm of EO mixture) and transferred to sterilized containers.

After the addition of the EOs, the wines were evaluated for aroma, taste and overall quality attributes using locally approved protocols in our laboratory, as previously reported [19]. All samples were served at $12-15{ }^{\circ} \mathrm{C}$ and a blind test in a colored glass under low light was followed. 
Then, (a) microbial spoilage, and (b) microbial growth after deliberate inoculation with spoilage microorganisms, were monitored at room $\left(18-20^{\circ} \mathrm{C}\right)$ or low temperature $\left(4^{\circ} \mathrm{C}\right)$, as described below.

\subsection{Analytical Procedures}

\subsubsection{GC/MS Analysis}

GC/MS analysis was carried out in a GC-MS (GC: 6890A, Agilent Technologies, USA; MSD: 5973, Agilent Technologies) using a Factor Four VF 1ms column $(25 \mathrm{~m}, 0.2 \mathrm{~mm}$ i.d., $0.33 \mu \mathrm{m}$ film thickness, Agilent Technologies), as described previously [10]. Identification was based on the comparison of the retention times and mass spectra of the volatile compounds to Willey/NIST 0.5 and in-house created libraries, as well as on the determination of kovats' retention indexes (KI) and comparison with those available in the literature.

\subsubsection{Antimicrobial Assays}

Screening of EOs Antimicrobial Activity by the Disc Diffusion Assay

The antimicrobial activity of $C$. medica and C. zeylanicum EOs, either separately or in combination (EO mixture), was initially tested using the disk diffusion assay, as described previously [10]. In brief, $0.1 \mathrm{~mL}$ of a microbial suspension in $\frac{1}{4}$ strength Ringer's solution (LabM) was spread on the suitable agar culture medium, providing initial inoculums of $10^{5}$ or $10^{7} \mathrm{cfu} / \mathrm{mL}$. Then, sterile paper disks (Whatman no. 2) of $5 \mathrm{~mm}$ diameter were placed onto the inoculated agar surface containing $5 \mu \mathrm{L}$ of the EOs or the EO mixture. After incubation, the inhibition zones were measured in $\mathrm{mm}$. Erythromycin was used as positive control for O. oeni and P. pentosaceus, gentamycin for G. cerinus and voriconazole for yeasts. All experiments were carried out in four replicates.

\section{Determination of Minimum Inhibitory (MIC), Non-Inhibitory (NIC) and Minimum Lethal} (MLC) Concentrations

Minimum inhibitory (MIC) and non-inhibitory concentration (NIC) for O. oeni and P. pentosaceus were determined as previously described [10]. Broth media with no inoculum and inoculated broths with no EOs were used as negative controls [10]. The calculation of MIC and NIC values was based on the Lambert-Pearson model (LPM) [20,21].

The common microdilution method [22-24] was followed for screening the activity of the EOs against G. cerinus, D. bruxellensis, C. zemplinina, H. uvarum, P. guilliermondii and Z. bailii and MIC determination (NIC determination was impossible), as application of the LPM model was not possible due to the high turbidity of G. cerinus culture broth, known as the "milky" effect [25] and yeast cell sedimentation. After incubation, cell growth was observed at $610 \mathrm{~nm}$. Erythromycin was used as positive control for O. oeni and P. pentosaceus, gentamycin for G. cerinus and voriconazole for yeasts.

Minimum lethal concentration (MLC) was determined as described before [10].

All experiments were carried out in four replicates.

Antimicrobial Activity in Wines-Containing EOs

Spoilage of low alcohol wines supplemented with EOs and stored at room temperature $\left(18-20^{\circ} \mathrm{C}\right)$ or at $4{ }^{\circ} \mathrm{C}$ was monitored by determining bacteria and yeast $/$ molds counts on BHI Agar (LabM) at $37^{\circ} \mathrm{C}$ and Malt extract agar (LabM) at $30^{\circ} \mathrm{C}$, respectively, for 2-5 days.

Similarly, low alcohol wines containing either C. medica or C. zeylanicum $\mathrm{EO}$ or in combination (EO mixture) were deliberately spiked with O. oeni, P. pentosaceus, G. cerinus, D. bruxellensis, C. zemplinina, H. uvarum, P. guilliermondii or Z. bailii, separately (initial inoculum of $10^{3} \mathrm{cfu} / \mathrm{mL}$ was applied) and stored at room temperature $\left(18-20{ }^{\circ} \mathrm{C}\right)$ and at $4{ }^{\circ} \mathrm{C}$. Samples were collected at various intervals to monitor the levels of the inoculated strains.

In both experiments, wines with no EOs were used as controls. 
All experiments were carried out in triplicate.

\subsection{Statistical Analysis}

The mean values are presented and standard deviation in MIC and NIC values determined by the Lambert-Pearson model (LPM) was calculated by Figure P.2.1 software (Figure P Software Incorporated, Hamilton, ON, Canada). Standard deviation estimation was not applicable when the common microdilution method was used.

The results were analyzed for statistical significance with analysis of variance (ANOVA). Duncan's multiple range test was applied to determine significant differences (coefficients, ANOVA tables and significance $(p<0.05)$ were computed using Statistica v.10.0, StatSoft, Tulsa, OK, USA).

\section{Results and Discussion}

\subsection{GC/MS Analysis}

GC/MS analysis provided data about the percentage content of the volatile compounds in the EOs and not their actual concentration. The main compounds detected by GC/MS were limonene $(38.46 \%)$ and linalool (35.44\%) in Citrus medica EO, whereas trans-cinnamic-aldehyde accounted for $63.58 \%$ of the area in Cinnamomum zeylanicum EO (Table 1).

Table 1. Relative percentage (\%) area of volatiles identified in Citrus medica and Cinnamomum zeylanicum essential oils (Eos) by GC/MS analysis.

\begin{tabular}{|c|c|c|c|}
\hline Compounds & $\mathrm{KRI}^{1}$ & C. medica (\% area) & C. zeylanicum (\% area) ${ }^{2}$ \\
\hline 3-Methyl-2-buten-1-ol & 740 & $\operatorname{Tr}$ & - \\
\hline cis-3-Hexenol & 831 & $\operatorname{Tr}$ & - \\
\hline Hexanol & 843 & $\operatorname{Tr}$ & - \\
\hline Isoamyl acetate & 854 & $\operatorname{Tr}$ & - \\
\hline Styrene & 870 & - & $\mathrm{Tr}$ \\
\hline Thujene & 920 & 0.29 & 0.30 \\
\hline$\alpha$-Pinene & 928 & 0.81 & 1.56 \\
\hline Camphene & 940 & - & 0.51 \\
\hline Hexyl acetate & 954 & $\operatorname{Tr}$ & - \\
\hline 6-Methyl-5-hepten2-one & 958 & 0.12 & - \\
\hline Sabinene & 962 & $\operatorname{Tr}$ & $\operatorname{Tr}$ \\
\hline$\beta$-Pinene & 967 & 0.79 & 0.47 \\
\hline Octanal & 977 & - & $\operatorname{Tr}$ \\
\hline Myrcene & 979 & 1.23 & - \\
\hline$\alpha$-Phellandrene & 996 & $\mathrm{Tr}$ & 1.36 \\
\hline$d$-3-Carene & 1004 & - & 0.13 \\
\hline$a$-Terpinene & 1008 & 0.16 & - \\
\hline p-Cymene & 1010 & 0.64 & 3.15 \\
\hline$\beta$-Phellandrene & 1017 & - & 3.67 \\
\hline Limonene & 1020 & 38.46 & - \\
\hline cis-Ocimene & 1022 & $\operatorname{Tr}$ & 0.07 \\
\hline Acetophenone & 1028 & - & $\operatorname{Tr}$ \\
\hline trans-Ocimene & 1032 & 0.19 & - \\
\hline$\gamma$-Terpinene & 1043 & 7.96 & $\operatorname{Tr}$ \\
\hline Sabinene hydrate & 1046 & - & $\operatorname{Tr}$ \\
\hline Epoxy linalool & 1052 & 0.10 & $\operatorname{Tr}$ \\
\hline Dehydro- $p$-cymene & 1066 & - & $\operatorname{Tr}$ \\
\hline Terpinolene & 1073 & 0.46 & 0.14 \\
\hline Nonanal & 1077 & $\operatorname{Tr}$ & - \\
\hline Linalool & 1084 & 35.44 & 4.22 \\
\hline Isoamyl valerate & 1086 & - & $\operatorname{Tr}$ \\
\hline Menth-2-en-1-ol & 1103 & - & $\operatorname{Tr}$ \\
\hline iso-Nerol & 1104 & - & $\operatorname{Tr}$ \\
\hline Camphor & 1114 & - & $\operatorname{Tr}$ \\
\hline iso-Geraniol & 1118 & $\operatorname{Tr}$ & - \\
\hline Phenyl propionaldehyde & 1119 & - & 0.28 \\
\hline$\beta$-Terpineol & 1121 & $\operatorname{Tr}$ & - \\
\hline Citronellal & 1127 & $\operatorname{Tr}$ & - \\
\hline
\end{tabular}


Table 1. Cont.

\begin{tabular}{|c|c|c|c|}
\hline Compounds & $\mathrm{KRI}^{1}$ & C. medica (\% area) & C. zeylanicum $(\% \text { area })^{2}$ \\
\hline iso-Citral & 1136 & $\operatorname{Tr}$ & - \\
\hline Menthadienol & 1139 & $\operatorname{Tr}$ & - \\
\hline Borneol & 1141 & - & $\operatorname{Tr}$ \\
\hline Cryptone & 1147 & - & $\operatorname{Tr}$ \\
\hline 4-Terpineol & 1153 & 0.54 & 0.28 \\
\hline$\alpha$-Terpineol & 1164 & 2.09 & 0.50 \\
\hline Hexyl butyrate & 1171 & $\operatorname{Tr}$ & - \\
\hline cis-Cinnamic aldehyde & 1174 & - & 0.48 \\
\hline Decanal & 1180 & - & $\operatorname{Tr}$ \\
\hline 3-Phenylpropanol & 1194 & - & $\mathrm{Tr}$ \\
\hline$o$-Anisaldehyde & 1199 & - & $\operatorname{Tr}$ \\
\hline Nerol & 1206 & 1.58 & - \\
\hline cis-Citral & 1210 & 1.88 & - \\
\hline trans-Cinnamic-aldehyde & 1230 & - & 63.58 \\
\hline Geraniol & 1231 & 2.34 & - \\
\hline trans-Citral & 1237 & 3.09 & - \\
\hline Phellandral & 1241 & - & $\operatorname{Tr}$ \\
\hline Safrole & 1255 & - & $\operatorname{Tr}$ \\
\hline Cinnamic alcohol & 1263 & - & 0.13 \\
\hline Thymol & 1264 & - & $\operatorname{Tr}$ \\
\hline Carvacrol & 1273 & - & $\operatorname{Tr}$ \\
\hline Eugenol & 1322 & - & 5.05 \\
\hline Terpinyl acetate & 1325 & $\operatorname{Tr}$ & - \\
\hline Hydrocinnamyl acetate & 1332 & - & $\mathrm{Tr}$ \\
\hline Neryl acetate & 1339 & 0.27 & - \\
\hline$\alpha$-Cubebene & 1339 & - & $\operatorname{Tr}$ \\
\hline cis-Cinnamyl acetate & 1350 & - & $\operatorname{Tr}$ \\
\hline Geranyl acetate & 1358 & 0.52 & - \\
\hline Copaene & 1364 & - & 0.74 \\
\hline Coumarine & 1369 & - & $\operatorname{Tr}$ \\
\hline$\beta$-Elemene & 1378 & - & $\operatorname{Tr}$ \\
\hline trans-Cinnamyl acetate & 1403 & - & 2.36 \\
\hline Caryophyllene & 1404 & & 5.92 \\
\hline$\alpha$-Humulene & 1439 & - & 1.08 \\
\hline Caryophyllene oxide & 1455 & - & 0.98 \\
\hline$o$-Methoxy cinnamic aldehyde & 1476 & - & 0.40 \\
\hline Valencene & 1478 & $\operatorname{Tr}$ & - \\
\hline Acetyl eugenol & 1483 & - & 0.25 \\
\hline$\beta$-Bisabolene & 1495 & 0.10 & - \\
\hline Geranyl-iso-butyrate & 1515 & $\operatorname{Tr}$ & - \\
\hline Geranyl butyrate & 1538 & $\operatorname{Tr}$ & - \\
\hline trans-Nerolidol & 1545 & $\operatorname{Tr}$ & - \\
\hline Benzyl benzoate & 1713 & - & 1.54 \\
\hline
\end{tabular}

1: Kováts Retention Indices, 2 : Tr: traces $(<0.10 \%)$.

\subsection{Antimicrobial Assays}

Considering that composition and thus effectiveness of EOs depends greatly upon a number of cultivation, environmental and climate factors [26-28], the antimicrobial activity of the two EOs separately or their mixture against Oenococcus oeni, Pediococcus pentosaceus, Gluconobacter cerinus, Dekkera bruxellensis, Candida zemplinina, Hanseniaspora uvarum, Pichia guilliermondii and Zygosaccharomyces bailii was initially confirmed using the disk diffusion method (data not shown). Subsequently, MIC and NIC (when applicable) values against the microbial species usually responsible for wine spoilage were assessed, as their precise determination is crucial for the food industry, in order to regulate the optimum amount of the antimicrobial agent to prevent microbial spoilage. The effective growth inhibition of both oils, separately or in combination, against all microbial species (Table 2) was documented, although MIC, NIC (when applicable) and MLC values were significantly $(p<0.05)$ higher compared to erythromycin, gentamycin and voriconazole (Table 2), which were used as positive controls. 
Table 2. Minimum inhibitory (MIC), non-inhibitory (NIC) and minimum lethal concentration (MLC) (mg/L) of Citrus medica and Cinnamomum zeylanicum EOs and their mixtures against common wine spoilage microbes. Erythromycin was used as positive control for Oenococcus oeni and Pediococcus pentosaceus, gentamycin for Gluconobacter cerinus and voriconazole for yeasts (standard deviation ranged in zero values if not shown). Application of the Lambert-Pearson model (LPM) and thus NIC determination for Gluconobacter cerinus, Dekkera bruxellensis, Candida zemplinina, Hanseniaspora uvarum, Pichia guilliermondii and Zygosaccharomyces bailii was impossible, due to the high turbidity of G. cerinus culture broth ("milky" effect) and yeast cell sedimentation.

\begin{tabular}{|c|c|c|c|c|c|c|c|c|c|c|c|c|c|c|c|c|c|c|}
\hline \multirow{2}{*}{ Microbial Species } & \multicolumn{3}{|c|}{ C. medica $\mathrm{EO}$} & \multicolumn{3}{|c|}{ C. zeylanicum EO } & \multicolumn{3}{|c|}{ EOs Mixture } & \multicolumn{3}{|c|}{ Erythromycin } & \multicolumn{3}{|c|}{ Voriconazole } & \multicolumn{3}{|c|}{ Gentamycin } \\
\hline & MIC & NIC & MLC & MIC & NIC & MLC & MIC & NIC & MLC & MIC & NIC & MLC & MIC & NIC & MLC & MIC & NIC & MLC \\
\hline G. cerinus & 2544 & - & 10176 & 1245 & - & 5978 & 2305 & - & 9222 & - & - & - & - & - & - & 4 & - & 8 \\
\hline O. oeni & $2097 \pm 25$ & $1081 \pm 34$ & 10176 & $1037 \pm 30$ & $202 \pm 40$ & 5978 & $2041 \pm 27$ & $687 \pm 18$ & 9222 & $0.24 \pm 0.001$ & $0.06 \pm 0.001$ & 1 & - & - & - & - & - & - \\
\hline P. pentosaceus & $2506 \pm 42$ & $1530 \pm 25$ & 10176 & $1549 \pm 40$ & $361 \pm 50$ & 5978 & $2089 \pm 18$ & $234 \pm 9$ & 9222 & $0.12 \pm 0.001$ & $0.06 \pm 0.002$ & 0.5 & - & - & - & - & - & - \\
\hline D. bruxellensis & 4240 & - & 12720 & 125 & - & 747 & 2305 & - & 13832 & - & - & - & 1 & - & 4 & - & - & - \\
\hline C. zemplinina & 636 & - & 1696 & 374 & - & 1494 & 350 & - & 1844 & - & - & - & 1 & - & 4 & - & - & - \\
\hline H. uvarum & 530 & - & 1696 & 498 & - & 1993 & 350 & - & 1844 & - & - & - & 1 & - & 4 & - & - & - \\
\hline P. guilliermondii & 636 & - & 1696 & 374 & - & 2491 & 350 & - & 1844 & - & - & - & 1 & - & 4 & - & - & - \\
\hline Z. bailii & 530 & - & 1272 & 498 & - & 5978 & 1752 & - & 7377 & - & - & - & 1 & - & 4 & - & - & - \\
\hline
\end{tabular}


Similarly, growth inhibition of C. medica EO against Aspergillus niger, Aspergillus flavus, Saccharomyces cerevisiae, Candida albicans and Pediococcus dextrinicus [10,29] and C. zeylanicum EO against Candida albicans and Pediococcus dextrinicus has been also evidenced previously [22,29].

\subsection{Sensory Trials}

To determine the maximum concentration of EOs resulting in products with acceptable sensory characteristics, an evaluation test was performed. According to the results (data not shown), the addition of EOs significantly affected $(p<0.05)$ all quality attributes.

Wines supplemented with $0.010 \%$ C. medica EO were characterized by a fruity and citrus-like aroma, while increasing concentrations of the added oil resulted in a pungent aroma and repellent taste. A sweet or sweet/sour taste was mostly predominant when C. zeylanicum was added (at $0.010 \%$ vol) and a warming effect was noticed when its concentration was increased. A mixture of both EOs at equal concentrations $(0.005 \%)$ resulted in a pleasant fruity/wine-like aroma and sweet/sour taste.

In all cases, concentrations higher than $0.010 \%$ were rejected, as they masked the wine flavor and oil residues formed an obvious layer on the top of the wine.

\subsection{Antimicrobial Activity of C. medica and C. zeylanicum EOs in Low Alcohol Wines}

Primarily, the effect of C. medica and C. zeylanicum EOs on the extension of the preservation time was investigated both separately and in combination. The oils were introduced in low alcohol wines $(\sim 6 \% \mathrm{vol})$ in concentrations $(0.010 \% v / v)$ lower than the MIC, as higher levels resulted in sensory faults. The results are presented in Figure 1. In both temperatures, a significant increase of the shelf-life was noticed. Specifically, at room temperature, spoilage in wines containing C. medica or C. zeylanicum EO or their mixture was observed after 18, 74 or 67 days, respectively, in contrast to 9 days in the control (wine with no EO). Likewise, at $4{ }^{\circ} \mathrm{C}$, the corresponding preservation days for wines supplemented with C. medica or C. zeylanicum $\mathrm{EO}$ or their mixture were 74, 109 and 88 days, while spoilage in the control sample was evidenced after 39 days.

Subsequently, the resistance of low alcohol wines supplemented with C. medica and C. zeylanicum EOs against the growth of spoilage microbes was further investigated. In this vein, wines supplemented with $C$. medica or $C$. zeylanicum EOs, either separately or in combination and wines with no EOs were deliberately inoculated with O. oeni, P. pentosaceus, G. cerinus, D. bruxellensis, C. zemplinina, H. uvarum, P. guilliermondii and Z. bailii, separately. Microbial growth was monitored at room temperature or refrigerated temperature (Figures 1 and 2). The results showed that in all cases microbial counts were significantly $(p<0.05)$ lower in wines supplemented with the EOs.

Cinnamon and citrus EOs or powders were previously proposed as preventing agents against microorganism-induced food spoilage and to secure microbial safety in fruit juices [30,31]. Likewise, the addition of cinnamon powder in unpasteurized apple cider resulted in $2 \operatorname{logcfu} / \mathrm{mL}$ reduction of Escherichia coli O157:H7 [32]. Additionally, lemongrass, cinnamon, or geraniol EOs inactivated Salmonella enteritidis, E. coli, and Listeria innocua in unpasteurized apple and pear juices [33]. Similarly, recent reports suggested that citrus EOs may represent a promising alternative for pathogens in fruit juices [34]. Specifically, Citrus limon oil was effective against E. coli O157:H7 and S. enterica in apple juice [35], while it led to germination inhibition and outgrowth of Acinetobacter acidoterrestris spores in lemon juice under refrigerated storage [36]. In the same manner, cinnamon EO in tyndallized carrot broth inhibited the spore germination of psychrotrophic Bacillus cereus at 8 or $12{ }^{\circ} \mathrm{C}$, but not at $16^{\circ} \mathrm{C}$ [37]. Other studies demonstrated the effective growth inhibition of E. coli O157:H7 and S. enterica in wine marinades supplemented with plant extracts and EOs from oregano, thyme and its derivatives and were considered suitable for meat products [38,39].

Hence, to the best of the authors' knowledge, the present study reports for the first time the effectiveness of $C$. medica and C. zeylanicum EOs in suppressing microbial growth in deliberately spiked low alcohol wines. 


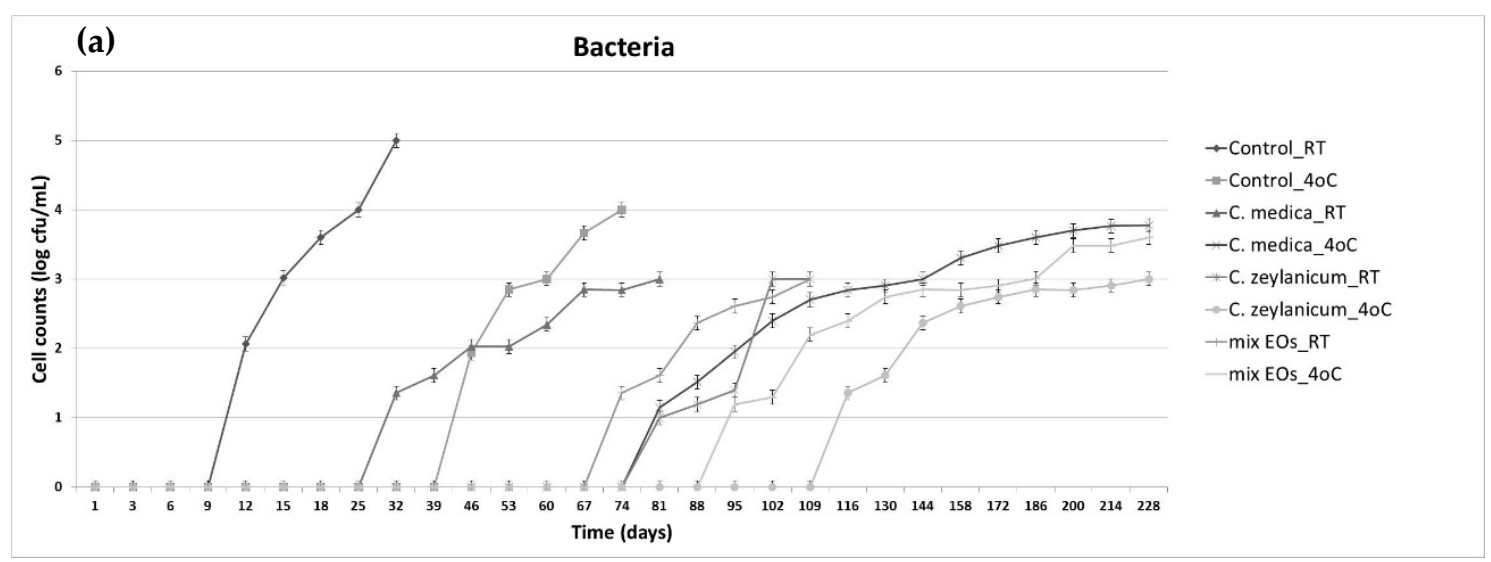

\section{(b)}

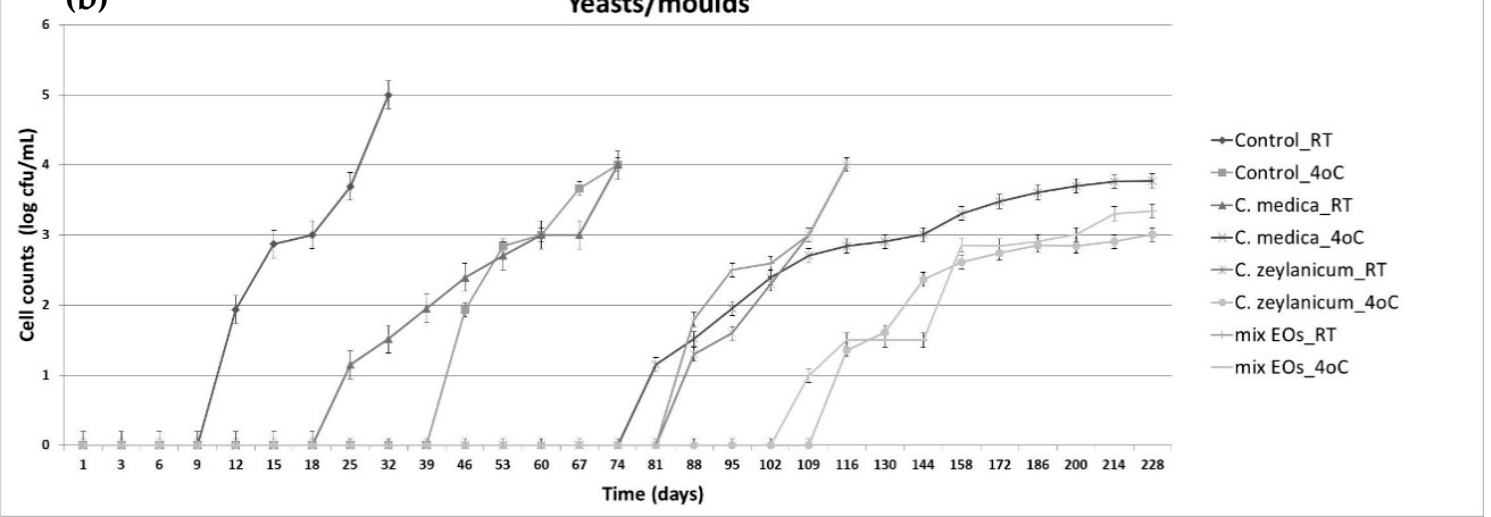

Figure 1. Effect of Citrus medica and Cinnamomum zeylanicum EOs on spoilage of low alcohol wines $\left(\sim 6 \%\right.$ vol) during storage at room temperature $\left(18-20{ }^{\circ} \mathrm{C}\right)$ or at $4{ }^{\circ} \mathrm{C}$. Wines were supplemented with either C. medica or C. zeylanicum EO $(0.010 \%)$ or their mixture $(0.005 \%$ of each oil). Wine with no EOs was used as control. (a) Bacteria counts, (b) Counts of yeasts/molds. Counts below the detection limit $(<10$ cells $/ \mathrm{mL})$ are indicated with 0 value.

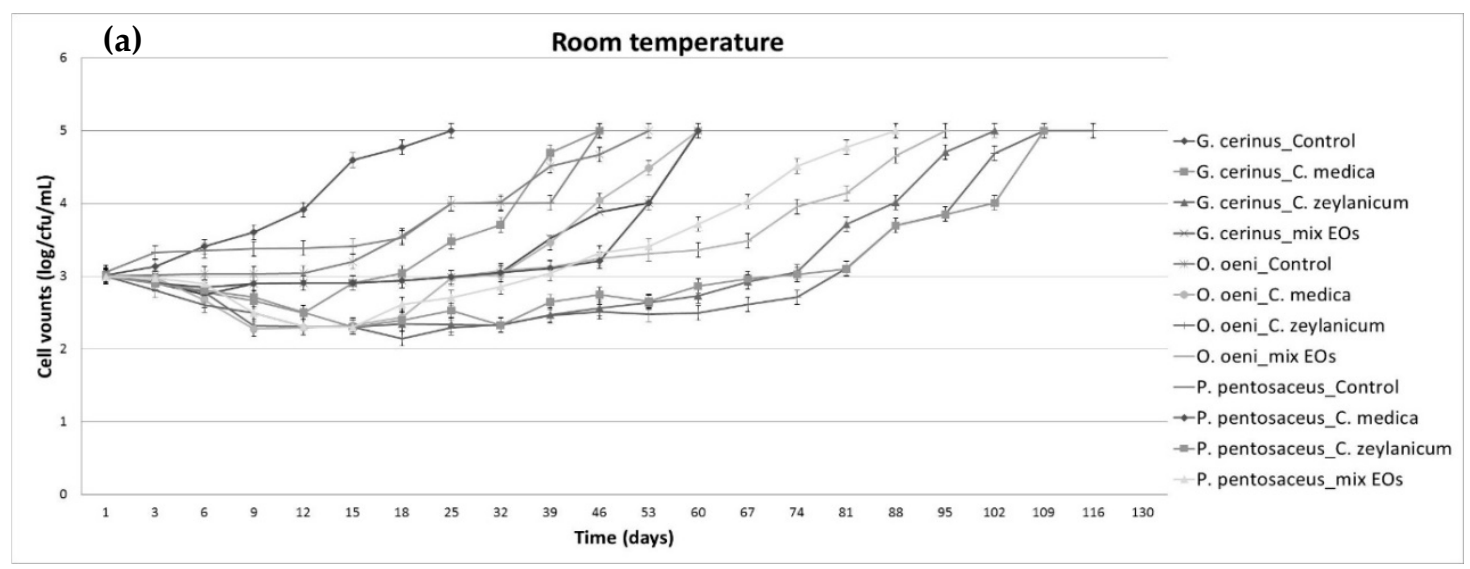

Figure 2. Cont. 


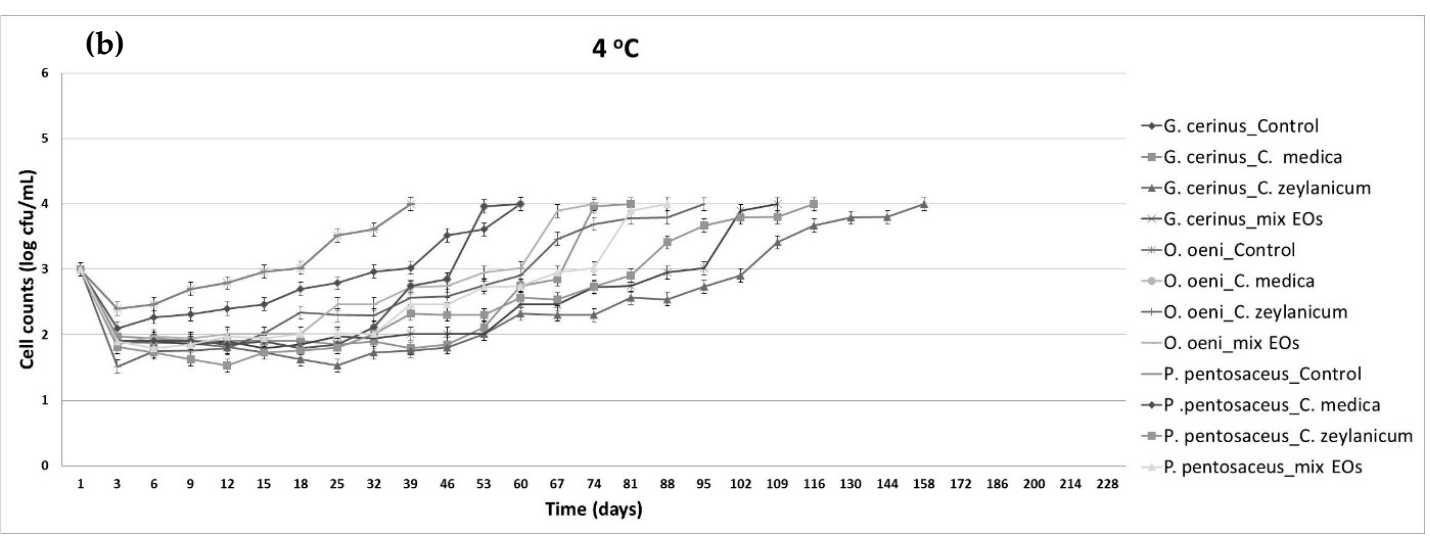

(c) Room temperature

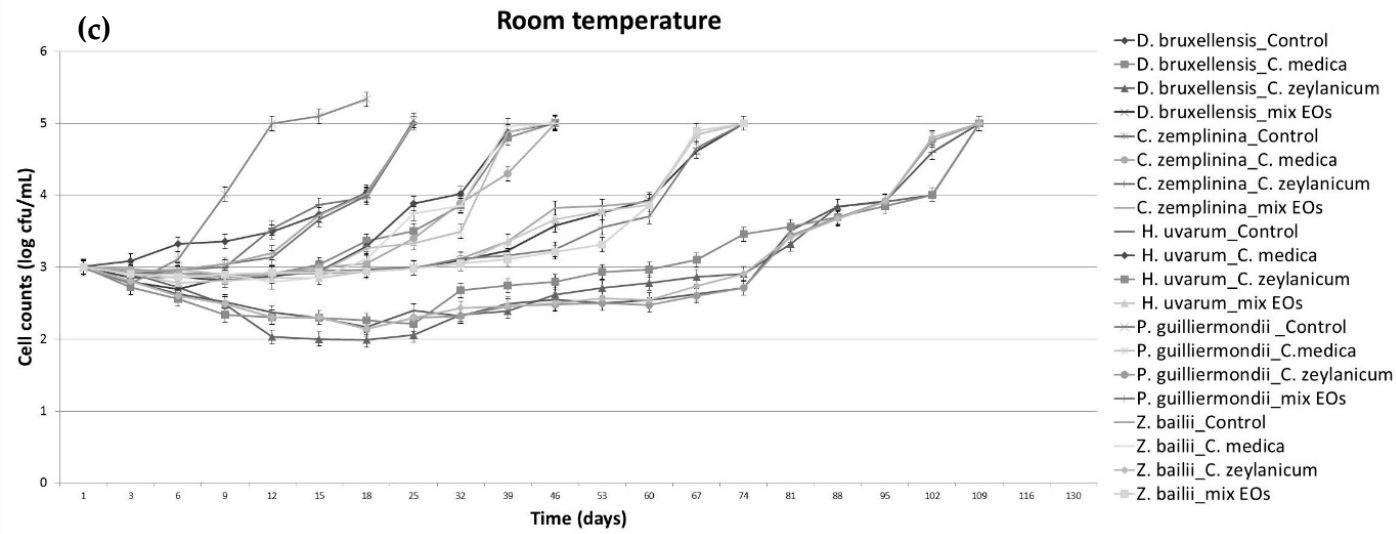

(d)

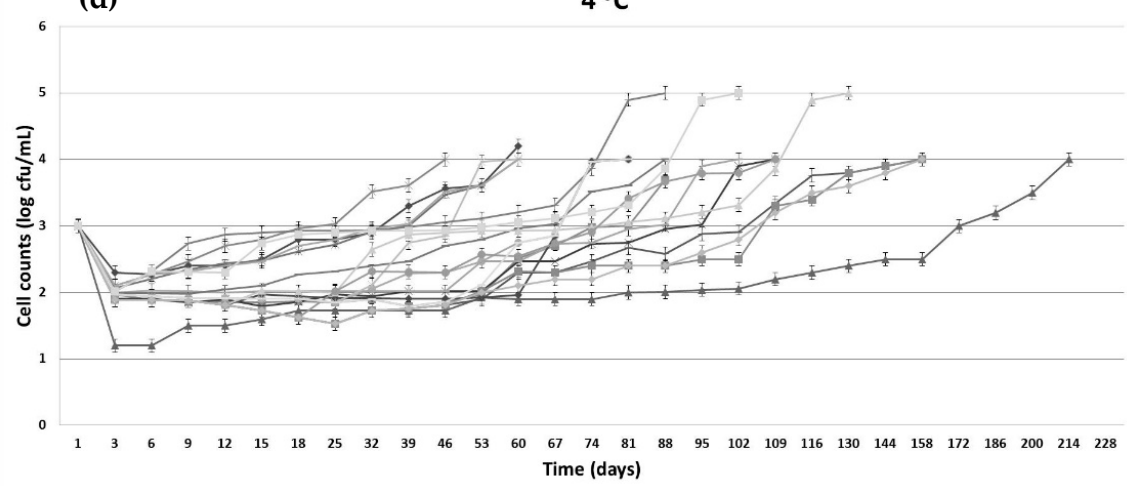

$\rightarrow$ D. bruxellensis Contro -D. bruxellensis_C. medica D. bruxellensis_C. zeylanicum -D. bruxellensis_mix EOs -C. zemplinina_C. medica -C. zemplinina_C. zeylanicum C. zemplinina_mix EOs -H. uvarum_Control $\rightarrow \mathrm{H}$. uvarum C. medica - H. uvarum_C. zeylanicum H. uvarum_mix EOs P. guilliermondii_Control P. guilliermondii_C. medica -P. guilliermondii_C. zeylanicum P. guilliermondii_mix EOS

Z. bailii_Control

Z. bailii_C. medica -Z. bailii_C. zeylanicum Z. bailii_mix EOs

Figure 2. Effect of Citrus medica and Cinnamomum zeylanicum EOs on microbial growth in deliberately spiked low alcohol wines $(\sim 6 \% \mathrm{vol})$ during storage at room temperature $\left(18-20{ }^{\circ} \mathrm{C}\right)$ and at $4{ }^{\circ} \mathrm{C}$. Wines were supplemented with either C. medica or C. zeylanicum EO $(0.010 \%)$ or their mixture $(0.005 \%$ of each oil). Wine with no EO was used as control. Gluconobacter cerinus, Oenococcus oeni and Pediococcus pentosaceus counts at room temperature (a) or at $4{ }^{\circ} \mathrm{C}$ (b). Dekkera bruxellensis, Candida zemplinina, Hanseniaspora uvarum, Pichia guillermndii and Zygosaccharomyces bailii counts at room temperature $(\mathbf{c})$ or at $4{ }^{\circ} \mathrm{C}(\mathbf{d})$.

\section{Conclusions}

The results showed that wine supplementation with $C$. medica or C. zeylanicum EOs separately or in combination led to considerable spoilage and microbial growth delay, promoting their use as effective antimicrobial agents in the wine industry. The observed effects may be attributed to the main 
bioactive constituents of the oils, but further testing using pure standard compounds may be useful to validate such a hypothesis, as well as to identify potential synergistic or antagonistic interactions, leading to even more specific industrial applications.

Author Contributions: Conceptualization, Y.K.; Data curation, A.N., V.S. and G.S.; Funding acquisition, Y.K.; Investigation, G.M. and A.N.; Methodology, G.M.; Project administration, Y.K.; Resources, Y.K.; Validation, G.M., A.N., V.S. and G.S.; Visualization, Y.K.; Writing—original draft G.M. and A.N.; Writing-review and editing, Y.K. All authors have read and agreed to the published version of the manuscript.

Funding: The project was funded by the Greek Operational Program "Human Resources Development, Education and Lifelong Learning, Support researchers with emphasis on young researchers". MIS 5006289: "Novel wine products using biopreservatives and probiotics", co-funded by the European Union (European Social Fund) and Greek National Funds, National Strategic Reference Framework (NSRF) 2014-2020.

Conflicts of Interest: The authors declare no conflict of interest.

\section{References}

1. Ferrer-Gallego, R.; Puxeu, M.; Martin, L.; Nart, E.; Hidalgo, C.; Andorra, I. Microbiological, Physical, and Chemical Procedures to Elaborate High-Quality SO2-Free Wines. In Grapes and Wines-Advances in Production, Processing, Analysis and Valorization, 1st ed.; Jordão, A.M., Cosme, F., Eds.; IntechOpen: London, UK, 2017; pp. 171-193. ISBN 978-953-51-3834-1. [CrossRef]

2. Inetianbor, J.E.; Yakubu, J.M.; Ezeonu, S.C. Effects of food additives and preservatives on a man-review. AJST 2015, 6, 1118-1135.

3. Irwin, S.V.; Fisher, P.; Graham, E.; Malek, A.; Robidoux, A. Sulfites inhibit the growth of four species of beneficial gut bacteria at concentrations regarded as safe for food. PLoS ONE 2017, 12, e0186629. [CrossRef] [PubMed]

4. Burt, S. Essential oils: Their antibacterial properties and potential applications in foods-A review. Int. J. Food Microbiol. 2004, 94, 223-253. [CrossRef] [PubMed]

5. Chorianopoulos, N.; Evergetis, E.T.; Aligiannis, N.; Mitakou, S.; Nychas, G.J.E.; Haroutounian, S.A. Correlation between chemical composition of Greek essential oils and their antibacterial activity against food-borne pathogens. Nat. Prod. Commun. 2007, 2, 419-426. [CrossRef]

6. Nychas, G.J.E.; Skandamis, P.; Tassou, C. Antimicrobials from herbs and spices. In Natural Antimicrobials for the Minimal Processing of Foods, 1st ed.; Roller, S., Ed.; Woodhead Publishing Limited: Cambridge, UK, 2003; pp. 176-200. ISBN 978-18-5573-669-6.

7. Chhikara, N.; Kour, R.; Jaglan, S.; Gupta, P.; Gat, Y.; Panghal, A. Citrus medica: Nutritional, phytochemical composition and health benefits-A review. Food Funct. 2018, 9, 1978-1992. [CrossRef] [PubMed]

8. Muhammad, D.R.A.; Dewettinck, K. Cinnamon and its derivatives as potential ingredient in functional food-A review. Int. J. Food Prop. 2017, 20, 2237-2263. [CrossRef]

9. De La Torre Torres, J.E.; Gassara, F.; Kouassi, A.P.; Brar, S.K.; Belkacemi, K. Spice Use in Food: Properties and Benefits. Crit. Rev. Food Sci. Nutr. 2015, 57, 1078-1088. [CrossRef]

10. Mitropoulou, G.; Fitsiou, E.; Spyridopoulou, K.; Tiptiri-Kourpeti, A.; Bardouki, H.; Vamvakias, M.; Panas, P.; Chlichlia, K.; Pappa, A.; Kourkoutas, Y. Citrus medica essential oil exhibits significant antimicrobial and antiproliferative activity. LWT-Food Sci. Technol. 2017, 84, 344-352. [CrossRef]

11. Li, Z.H.; Cai, M.; Liu, Y.S.; Sun, P.L.; Luo, S.L. Antibacterial Activity and Mechanisms of Essential Oil from Citrus medica L. var. sarcodactylis. Molecules 2019, 24, 1577. [CrossRef]

12. Liu, Q.; Meng, X.; Li, Y.; Zhao, C.-N.; Tang, G.-Y.; Li, H.-B. Antibacterial and antifungal activities of spices. Int. J. Mol. Sci. 2017, 18, 1283. [CrossRef]

13. Vasconcelos, N.G.; Croda, J.; Simionatto, S. Antibacterial mechanisms of cinnamon and its constituents: A review. Microb. Pathog. 2018, 120, 198-203. [CrossRef] [PubMed]

14. Kumar, S.; Kumari, R.; Mishra, S. Pharmacological properties and their medicinal uses of Cinnamomum: A review. J. Pharm. Pharmacol. 2019, 71, 1735-1761. [CrossRef]

15. Mustafa, N.E. Citrus Essential Oils: Current and prospective uses in the food industry. Recent Pat. Food Nutr. Agric. 2015, 7, 115-127. [CrossRef] [PubMed]

16. Chorianopoulos, N.; Skandamis, P.; Nychas, G.J.E.; Haroutounian, S.A. Use of essential oil treatments to control the Listeria monocytogenes growth in various food commodities. Planta Med. 2008, 74, 131. [CrossRef] 
17. Tsimogiannis, D.; Choulitoudi, E.; Bimpilas, A.; Mitropoulou, G.; Kourkoutas, Y.; Oreopoulou, V. Exploitation of the biological potential of Satureja thymbra essential oil and distillation by-products. J. Appl. Res. Med. Aromat. Plants 2017, 4, 12-20. [CrossRef]

18. Hyldgaard, M.; Mygind, T.; Meyer, R.L. Essential oils in food preservation: Mode of action, synergies, and interactions with food matrix components. Front. Microbiol. 2012, 3, 12. [CrossRef]

19. Nikolaou, A.; Tsakiris, A.; Kanellaki, M.; Bezirtzoglou, E.; Akrida-Demertzi, K.; Kourkoutas, Y. Wine production using free and immobilized kefir culture on natural supports. Food Chem. 2019, 272, 39-48. [CrossRef]

20. Chorianopoulos, N.G.; Lambert, R.J.W.; Skandamis, P.N.; Evergetis, E.T.; Haroutounian, S.A.; Nychas, G.J.E. A newly developed assay to study the minimum inhibitory concentration of Satureja spinosa essential oil. J. Appl. Microbiol. 2006, 100, 778-786. [CrossRef]

21. Lambert, R.J.; Lambert, R. A model for the efficacy of combined inhibitors. J. Appl. Microbiol. 2003, 95, 734-743. [CrossRef]

22. Khan, R.; Islam, B.; Akram, M.; Shakil, S.; Ahmad, A.; Ali, M.; Siddiqui, M.; Khan, A. Antimicrobial activity of five herbal extracts against multi drug resistant (MDR) strains of bacteria and fungus of clinical origin. Molecules 2009, 14, 586-597. [CrossRef]

23. Alastruey-Izquierdo, A.; Melhem, M.S.; Bonfietti, L.X.; Rodriguez-Tudela, J.L. Susceptibility test for fungi: Clinical and laboratory correlations in medical mycology. Rev. Inst. Med. Trop. Sao Paulo 2015, 57, 57-64. [CrossRef] [PubMed]

24. Clinical and Laboratory Standards Institute (CLSI). Reference Method for Broth Dilution Antifungal Susceptibility Testing of Yeast, Approved Standard, 4th ed.; CLSI standard M27; CLSI: Wayne, PA, USA, 2017; ISBN 1-56238-826-6.

25. Gomes, R.J.; Borges, M.F.; Rosa, M.F.; Castro-Gómez, R.; Spinosa, W.A. Acetic acid bacteria in the food industry: Systematics, characteristics and applications. Food Technol. Biotechnol. 2018, 56, 139-151. [CrossRef] [PubMed]

26. Aboukhalid, K.; Al Faiz, C.; Douaik, A.; Bakha, M.; Kursa, K.; Agacka-Mołdoch, M.; Machon, N.; Tomi, F.; Lamiri, A. Influence of environmental factors on essential oil variability in Origanum compactum Benth. Growing wild in Morocco. Chem. Biodivers. 2017, 14, 9. [CrossRef] [PubMed]

27. Chorianopoulos, N.; Kalpoutzakis, E.; Aligiannis, N.; Mitaku, S.; Nychas, G.J.; Haroutounian, S.A. Essential oils of Satureja, Origanum and Thymus species: Chemical composition and antibacterial activities against foodborne pathogens. J. Agric. Food Chem. 2004, 52, 8261-8267. [CrossRef] [PubMed]

28. Shams, M.; Ramezani, M.; Zandi, E.S.; Zandi, E.E.; Dursun, A.; Yildirim, E. Effects of climatic factors on the quantity of essential oil and dry matter yield of Coriander (Coriandrum sativum L.). IJST 2016, 9, 1-4. [CrossRef]

29. Khorsandi, A.; Ziaee, E.; Shad, E.; Razmjooei, M.; Eskandari, M.; Aminlari, M. Antibacterial effect of essential oils against spoilage bacteria from vacuum-packed cooked cured sausages. J. Food Prot. 2018, 81, 1386-1393. [CrossRef]

30. Ceylan, E.; Fung, D.; Sabah, J. Antimicrobial activity and synergistic effect of cinnamon with sodium benzoate or potassium sorbate in controlling Escherichia coli O157:H7 in apple juice. J. Food Sci. 2004, 69, 102-106. [CrossRef]

31. Yuste, J.; Fung, D.Y.C. Inactivation of Listeria monocytogenes Scott A 49594 in apple juice supplemented with cinnamon. J. Food Prot. 2002, 65, 1663-1666. [CrossRef]

32. Iu, J.; Mittal, G.S.; Griffiths, M.W. Reduction in levels of Escherichia coli O157:H7 in apple cider by pulsed electric fields. J. Food Prot. 2001, 64, 964-969. [CrossRef]

33. Raybaudi-Massilia, R.M.; Mosqueda-Melgar, J.; Martín-Belloso, O. Antimicrobial activity of essential oils on Salmonella enteritidis, Escherichia coli, and Listeria innocua in fruit juices. J. Food Prot. 2006, 69, 1579-1586. [CrossRef]

34. Mahato, N.; Kavita, S.; Rakoti, K.; Mukty, S.; EkRaj, B.; Moo, H.C. Citrus essential oils: Extraction, authentication and application in food preservation. Crit. Rev. Food Sci. Nutr. 2019, 59, 611-625. [CrossRef] [PubMed]

35. Friedman, M.; Henika, P.; Levin, C.; Mandrell, R. Antibacterial activities of plant essential oils and their components against Escherichia coli O157:H7 and Salmonella enterica in apple juice. J. Agric. Food Chem. 2004, 52, 6042-6048. [CrossRef] [PubMed] 
36. Maldonado, M.C.; Aban, M.P.; Navarro, A.R. Chemicals and lemon essential oil effect on Alicyclobacillus acidoterrestris viability. Braz. J. Microbiol. 2013, 44, 1133-1137. [CrossRef] [PubMed]

37. Hernández-Herrero, L.A.; Giner, M.J.; Valero, M. Effective chemical control of psychrotrophic Bacillus cereus EPSO-35AS and INRA TZ415 spore outgrowth in carrot broth. Food Microbiol. 2008, 25, 714-721. [CrossRef]

38. Friedman, M.; Henika, P.; Levin, C. Bactericidal activities of health-promoting, food-derived powders against the foodborne pathogens Escherichia coli, Listeria monocytogenes, Salmonella enterica, and Staphylococcus aureus. J. Food Sci. 2013, 78, 270-275. [CrossRef]

39. Friedman, M.; Levin, C.; Henika, P. Addition of phytochemical-rich plant extracts mitigate the antimicrobial activity of essential oil/wine mixtures against Escherichia coli O157:H7 but not against Salmonella enterica. Food Control 2017, 73, 562-565. [CrossRef]

(C) 2020 by the authors. Licensee MDPI, Basel, Switzerland. This article is an open access article distributed under the terms and conditions of the Creative Commons Attribution (CC BY) license (http://creativecommons.org/licenses/by/4.0/). 